\title{
Visualization Experiment and Numerical Simulation of Cracks Caused by Pulsed- Plasma Rock Fracturing
}

\author{
Zhaoxuan Li", Tie Yan, Zhaokai Hou, Wenfeng Sun and Yang Shao \\ College of Petroleum Engineering, Northeast Petroleum University, Daqing 163318, China
}

Received 5 April 2020; Accepted 29 June 2020

\begin{abstract}
Shale oil and gas reservoirs, as well as compact oil and gas reservoirs, are important oil exploration resources. However, their tight lithology and extremely low permeability and porosity hinder extraction. Production stimulation measures, such as reservoir fracturing transformation, are needed to increase production by low-permeability oil and gas reservoirs. This study explored a new type of fracturing technology, namely, pulsed-plasma rock fracturing, to increase rock fracturing efficiency and recovery. First, a model of stress distribution on the sidewalls of open holes was established. Then, a fracturing experiment was conducted on polymethyl methacrylate (PMMA). Morphological features were analyzed on the basis of the visual characteristics of PMMA, and the influential factors of fracture breakdown were summarized. Meanwhile, the stress-changing rule was analyzed by simulating pulsed-plasma shock-wave rock fracturing with LS-DYNA. Results show that pulsed-plasma fracturing can generate valid cracks with actiniform and wave-form features. High discharge voltages and loads on rocks associate with long crack lengths. In the simulation, applies load strengths form $9 \mathrm{MPa}$ to $30 \mathrm{MPa}$, and the crack lengths increase from $16 \mathrm{~mm}$ to $67.5 \mathrm{~mm}$. At the same time, the width and number of fractures show an increasing trend, and radioactivity and multi-branched cracks inside the rocks become increasingly complex. This study provides a practical and reliable reference for the technology of pulsed-plasma rock fracturing.
\end{abstract}

Keywords: Fracturing, Pulsed-plasma, Electrohydraulic cracking, Fracture visualization

\section{Introduction}

The world has invested massive amounts of manpower and material resources in technologies for increasing oil production. Fracturing is one of the important means for increasing oil production. However, the formation of effective fractures in hard rock formations has always troubled scholars in China and other countries. Pulsedplasma fracturing technology is one of the latest fracturing technologies with the greatest potential developed in recent years. As early as 1905, Swedbery found that high-voltage discharge in water can generate pulsed-plasma shock waves. This phenomenon was called "electrohydraulic effect" by succeeding scholars. In the subsequent dozens of years, scholars from Russia, Australia, France, China, the U.S.A, and Ukraine devoted themselves to studies on relevant technologies[1-5]. This technology was introduced in China to deblock oil layers. Related studies and applications have been performed in Zhongyuan Oilfield[6], Karamay Oilfield[7], Qiaokou Oilfield[8], and Henan Oilfield[9]. First, pulsed-plasma shock waves induce cracks in a reservoir, and internal fluid resonates. Second, the high-temperature plasma beam dissolves waxes and asphaltenes. On the basis of this effect, the blocking oil layer can be dredged with the efficiency of $90 \%$. Given that pulsed-plasma shock waves can crack reservoirs, scholars all over the world have applied this technology in rock breaking and fracturing. Pulsedplasma fracturing technology has attracted the attention of a

*E-mail address: lizhoox_zi@126.com

ISSN: 1791-2377 @ 2020 School of Science, IHU. All rights reserved. doi:10.25103/jestr.134.24 large number of scholars given its natural advantage over the present fracturing technology, which often pollutes reservoirs and wastes water resources. Scholars have mainly studied plasma-generating mechanisms, performed shockwave numerical simulation, developed experimental devices, and optimized the factors that influence fracturing effects [10-14].

In this study, laboratory experiments were conducted to study further the law of crack initiation with pulsed-plasma rock fracturing technology. A model of stress distribution on the sidewalls of open holes was established by using LSDYNA to simulate the process of pulsed-plasma shock-wave rock fracturing. Meanwhile, by visualizing the characteristics of polymethyl methacrylate (PMMA), a fracturing experiment was carried out to analyze and observe the morphological features and macro features of cracks to summarize the influential factors of crack initiation.

\section{State of the art}

Scholars have performed numerous works on pulsed-plasma fracturing technology. South Korean scholars Rim et al.[15] developed a rotating arc gap-switch that is driven by a selfinduced magnetic field with the voltage of $3-11 \mathrm{kV}$ and the peak current of $400 \mathrm{kA}$. They adopted a copper-tungsten electrode to improve switching performance. Experiments have shown that intense electromagnetic radiation occurs and the electric circuit exhibits sharp changes in current and voltage during plasma generation. Decun et al.[16] imposed anti-interference measures for laboratory equipment to solve these problems. Their discharge system was powered by 
single-phase $50 \mathrm{~Hz}, 220 \mathrm{~V}$ AC power supply to avoid the conduction coupling interference caused by the grid supply. Their experimental instrument adopted a piezoresistive pressure sensor to avoid electromagnetic interference. Sun et al.[17] conducted follow-up studies. They developed pulsed power with the power input of $220 \mathrm{~V}$ and $2 \mathrm{~kW}$, maximum stored energy of $40 \mathrm{~kJ}$, rated high DC voltage of $20 \mathrm{kV}$, and maximum discharge current of $70 \mathrm{kA}$. They utilized optical fiber to isolate and transmit high-voltage signals between the high-voltage unit and the control system. Scholars have not only developed devices but also crushed rocks to verify the feasibility of this device. For example, Bing from Dalian University of Technology developed a large-scale highpressure liquid-phase discharge device with the length of $5 \mathrm{~m}$ and the maximum discharge voltage of $30 \mathrm{kV}$ to test impulse shock-wave pressure in water and fitted the calculation formula of the shock-wave peak pressure [18.19]. Kuznetsova et al. [20] from the Institute of High-Tech Physics of Tomsk Polytechnic University in Russia conducted experiments on concrete blocks with dimensions of $620 \mathrm{~mm} \times 580 \mathrm{~mm} \times 1000 \mathrm{~mm}$ and $700 \mathrm{~mm} \times 450 \mathrm{~mm} \times$ $300 \mathrm{~mm}$. The high-voltage pulse device they developed has a voltage of 15-20 kV and the specific energy of $60 \mathrm{~kJ} / \mathrm{cm} 3$ and exhibits energy accumulation in the discharge channel of up to $2.5 \times 103 \mathrm{MPa}$. Khomeriki et al.[21] studied the directed fracture of rocks under impulse load. Madhavan et al.[22] performed one-dimensional and two-dimensional hydrodynamic simulations to study the action of shock waves on rocks in water. Chen and Maurel[23] established a simplified model of shock wave propagation in water under liquid-phase discharge to study the propagation law of pulsed-plasma shock waves in water and within surrounding rocks. French scholars Deroy and Claverie[24.25] experimentally studied the formation of plasma and the propagation of pulsed-plasma shock waves. By using optical and imaging diagnostic methods, they observed shock wave propagation and bubble formation and estimated the energy absorbed in water during discharge. Yi et al.[26] discussed the influences of optimal gaps between electrodes and plasma channel length on the intensity of pulsed-plasma shock waves. The most intense pulsed-plasma shock wave can be produced with the optimal electrode gap. The plasma channel length adjustment (PCLR) method can effectively improve the efficiency of energy transfer and reduce the requirements for capacitors and switches. In addition, the PCLR method has been applied to demonstrate that pulsedplasma shock waves can improve permeability effectively. Given that this experiment was carried out in an environment without confining pressure, future experiments applied the triaxial condition. Mao [27] studied the possibility of multiple cracking and predicted the size of cracks through a triaxial pressure simulation experiment. Meanwhile, pulse attenuation has been explained by using a dynamic fracture model. Multiple cracks with ideal lengths and widths are induced when the pressure amplitude generated by the pulsed-pressure wave reaches $50 \mathrm{MPa}$. Experiments have shown that liquid-phase high-voltage pulsed-discharge cracking technology can be used not only for compact reservoirs but also for oriented cracking. Rongyao et al.[28] conducted three-dimensional topographic analysis on cracks generated by simulated rock cracking with the maximum storage energy of the same pulse power supply of $40 \mathrm{~kJ} / 20 \mathrm{kV}$. The cracks exhibit surface roughness values of $0.430-1.075 \mathrm{~mm}$ and certain conductivity. An electrical impulse fracturing device with a hydrostatic pressure of up to $30 \mathrm{MPa}$ has been established to simulate ambient pressure at the depth of $3000 \mathrm{~m}$ in deep wells. A plasma impact fracturing experiment at different hydrostatic pressures has also been conducted. This experiment showed that numerous short cracks are present, and crack turning is common. Annular cracks are found in local areas[29]. The groups of Yan[30],Usov[31] and Inoue[32]also conducted relevant experimental studies on this problem.

The above-mentioned studies discussed hydroelectric crushing mechanisms, experimental equipment, occurrence process, and action results. However, research systems established on the basis of theory for experimentation and simulation remains scant. The impossibility of observing the development of cracks inside test objects and understanding the trajectory of pulsed-plasma shock waves when rocks are cracked by plasma remains the major problem in experimental research. In this study, PMMA was used as an experimental object to observe the propagation path of pulsed-plasma shock waves in an ideal state.

The rest of the study is organized as follows. Section III describes how the model of stress distribution at the sidewalls of open holes was established, how the plasma fracturing experimental equipment was built independently, how the PMMA visualization experiment was carried out, and how the numerical model was constructed by using LSDYNA. As described in Section IV, pulsed-plasma fracturing was analyzed, the difference between pulsedplasma fracturing and hydraulic fracturing was compared, and the results of the numerical model were analyzed and discussed. The summary and relevant conclusions of this study are given in the last section.

\section{Methodology}

\subsection{Model of stress distribution on the sidewalls of open} holes and shock-wave pressure at fracture

Analyzing the instaneous stress conditions of rock rupture on the sidewalls of open holes reveals that when the permeability of the formation is low, the rock is subjected mainly to ground stress, fluid column pressure inside a wellbore, and the pressure of plasma-generating shock waves. The fluid column pressure of the rock, the pressure of the plasma-generating shock waves, and the ground stress are studied, and the final field distribution of the stress on the surrounding rock sidewall is obtained via the superposition principle. The stress conditions of the well sidewall include radial stress $\left(\sigma_{r}\right)$, vertical stress $\left(\sigma_{Z}\right)$, and circumferential stress $\left(\sigma_{\theta}\right)$. The pressure stress is positive, and the pulling stress is negative. The distribution of the stress field surrounding the well sidewall is shown in Fig. 1.

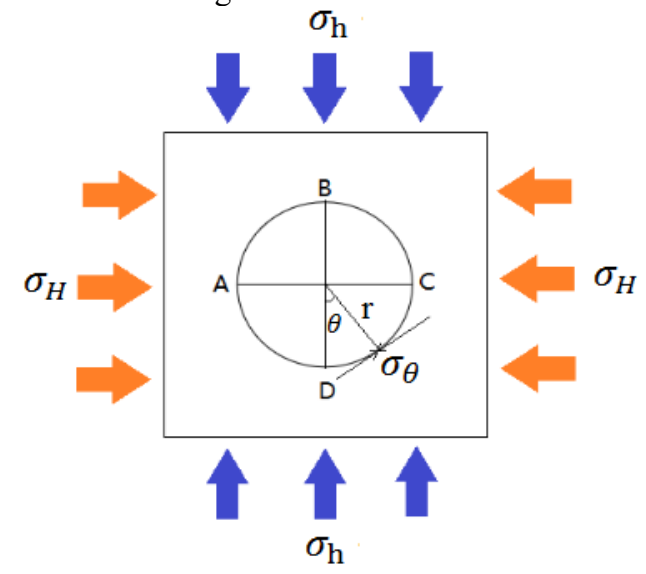

Fig. 1. Distribution of the stress field surrounding the well sidewall 
Stress of fluid column pressure $p_{w}$ on the well sidewall:

$$
\left\{\begin{array}{c}
\sigma_{r}=p_{w} \\
\sigma_{\theta}=-p_{w}
\end{array}\right.
$$

Stress of the shock wave $p_{m}$ generated by plasma on the well sidewall:

$$
\left\{\begin{array}{c}
\sigma_{r}=p_{m} \\
\sigma_{\theta}=-p_{m}
\end{array}\right.
$$

Stress of the maximum horizontal main stress $\sigma_{H}$ on the well sidewall:

$$
\sigma_{\theta}=\sigma_{H}-2 \sigma_{H} \cos 2 \theta
$$

Stress of the minimum horizontal main stress $\sigma_{h}$ on the well sidewall:

$\sigma_{\theta}=\sigma_{h}+2 \sigma_{h} \cos 2 \theta$

Stress of the overlaying strata pressure $\sigma_{V}$ on the well sidewall:

$$
\sigma_{Z}=\sigma_{V}-2 v\left(\sigma_{H}-\sigma_{h}\right) \cos 2 \theta
$$

where $v$ is Poisson's ratio and is dimensionless.

In accordance with the superposition principle, under the joint actions of fluid column pressure, shock-wave pressure, and ground stress, the distribution of formation stress on the well sidewall is as follows:

$$
\begin{aligned}
& \sigma_{r}=p_{w}+p_{m} \\
& \sigma_{\theta}=-p_{w}-p_{m}+\sigma_{H}-2 \sigma_{H} \cos 2 \theta+\sigma_{h}+2 \sigma_{h} \cos 2 \theta \\
& \sigma_{Z}=\sigma_{V}-2 v\left(\sigma_{H}-\sigma_{h}\right) \cos 2 \theta
\end{aligned}
$$

The rock breaks because the circumferential stress acting on the rock is larger than the extension strength of rock, that is:

$$
\sigma_{\theta}=-S_{t}
$$

Where $S_{t}$ is the extension strength of the rock in MPa.

As can be seen from Equation (7), when the shock-wave pressure $p_{m}$ increases, the circumferential stress $\sigma_{\theta}$ decreases. When $\sigma_{\theta}$ is negative, that is, the circumferential stress on the rock is converted into extension stress, the rock breaks if the extension stress is sufficient to overcome the extension strength when $\sigma_{\theta}$ is the minimum and $\theta$ is $0^{\circ}$ or $180^{\circ}$.

$\sigma_{\theta}=3 \sigma_{h}-p_{w}-p_{m}-\sigma_{H}-\alpha p_{p}$

where $p_{p}$ is pore pressure in $\mathrm{MPa}$, and $\alpha$ is the dimensionless effective stress coefficient.
Substituting Equation (10) into Equation (9) reveals that when the rock breaks, the pressure of the shock wave is $p_{m}$.

$p_{m}=3 \sigma_{h}-\sigma_{H}-p_{w}-\alpha p_{p}+S_{t}$

As can be seen from Equation (11), the extent of the rock-fracturing pressure is related to the rock extension strength, maximum horizontal principle stress, minimum horizontal principle stress, and pore pressure. Small differences between three times the minimum horizontal principle stress and the maximum principle stress indicate that the shock-wave pressure required by rock fracturing is low. Large pore pressure or fluid column pressure indicates that rock fracturing requires a low shock-wave pressure. Without applying confining pressure, the fracturing pressure of the rock is approximately equal to the extension strength of the rock.

3.2 Experimental device and method for the pulsedplasma fracturing of PMMA

(1) Experimental equipment

A pulsed-plasma fracturing experimental device through which plasma fracturing can occur simultaneously at different angles of a rock and in multiple holes is built in this study. The experimental device has two modules for charging, energy storage, and plasma generation. It includes a charging source, a discharge switch, a capacitor, a highvoltage protection inductor, a protective freewheeling diode, a discharge electrode set, and a pressure sensor. The connections of the pulsed-plasma fracturing experimental device are shown in Fig. 2.

(2) Experimental method

PMMA was visualized to summarize the fracturing law and observe cracks visually. First, six $100 \mathrm{~mm} \times 100 \mathrm{~mm}$ PMMA blocks were selected. A hole with the diameter of 30 $\mathrm{mm}$ and the depth of $60 \mathrm{~mm}$ was drilled into the middle of the upper surface of the PMMA, which was filled with water. Then, the electrode set was placed in the hole and sealed for the experiment. The schematic of the experimental device is shown in Fig. 3. Plasma fracturing experiments were carried out on 5 pieces of PMMA at 3, 4, 5, 6, and $7 \mathrm{kV}$ to observe fracture morphology. The last piece of PMMA was hydraulically fractured at $8 \mathrm{MPa}$ with a displacement of 30 $\mathrm{ml} / \mathrm{min}$ to compare the differences between the morphology of cracks induced by hydraulic fracturing and plasma fracturing.

\subsection{Establishment of the numerical model of pulsed-} plasma rock fracturing

A shock wave generated by a plasma pulse was simulated by applying a time-varying pulse load in the fluid domain to study further the mechanism of pulsed-plasma rock fracturing. In this experiment, the Euler algorithm was adopted in the fluid domain, and the Lagrangian algorithm was adopted in the rock specimen. The nonlinear coupling effect of the shock wave and the rock mass domain was realized by using the multi-material fluid-solid coupling algorithm. The failure control algorithm was stress control failure, that is, failure occurred when the tensile stress exceeded the tensile strength of the rock. The physical model was specified as a homogeneous rock with the dimensions of $150 \mathrm{~mm} \times 150 \mathrm{~mm} \times 150 \mathrm{~mm}$. The middle of the rock contained a hole with the diameter of $50 \mathrm{~mm}$ and the depth of $60 \mathrm{~mm}$. The fracturing experiment was 
Zhaoxuan Li, Tie Yan, Zhaokai Hou, Wenfeng Sun and Yang Shao/

Journal of Engineering Science and Technology Review 13 (4) (2020) 232 - 239

conducted on the model by using falling triangular pulse

loads of $9,12,15,20$, and $30 \mathrm{MPa}$.

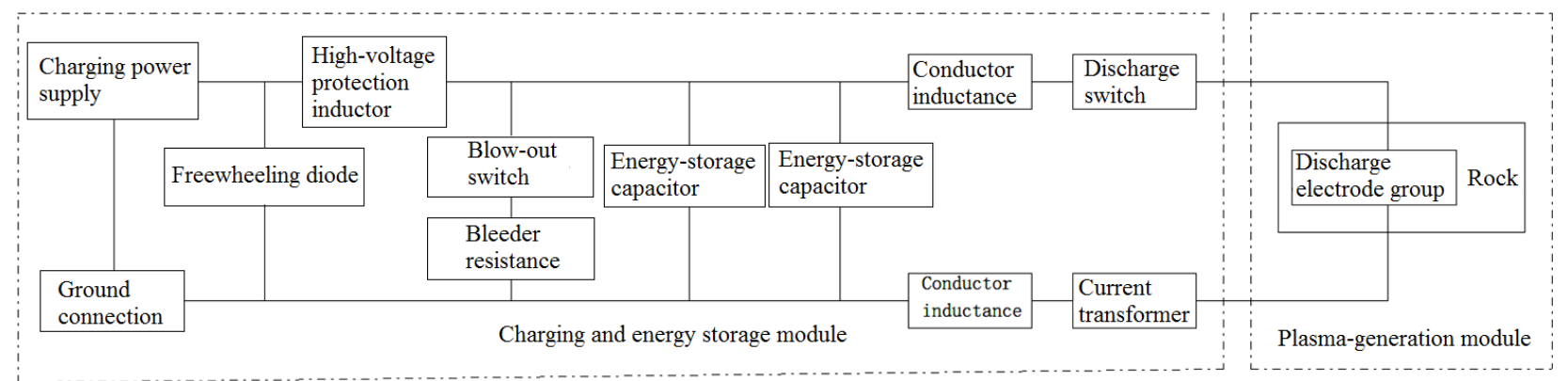

Fig. 2. Connections of pulsed-plasma fracturing experimental device

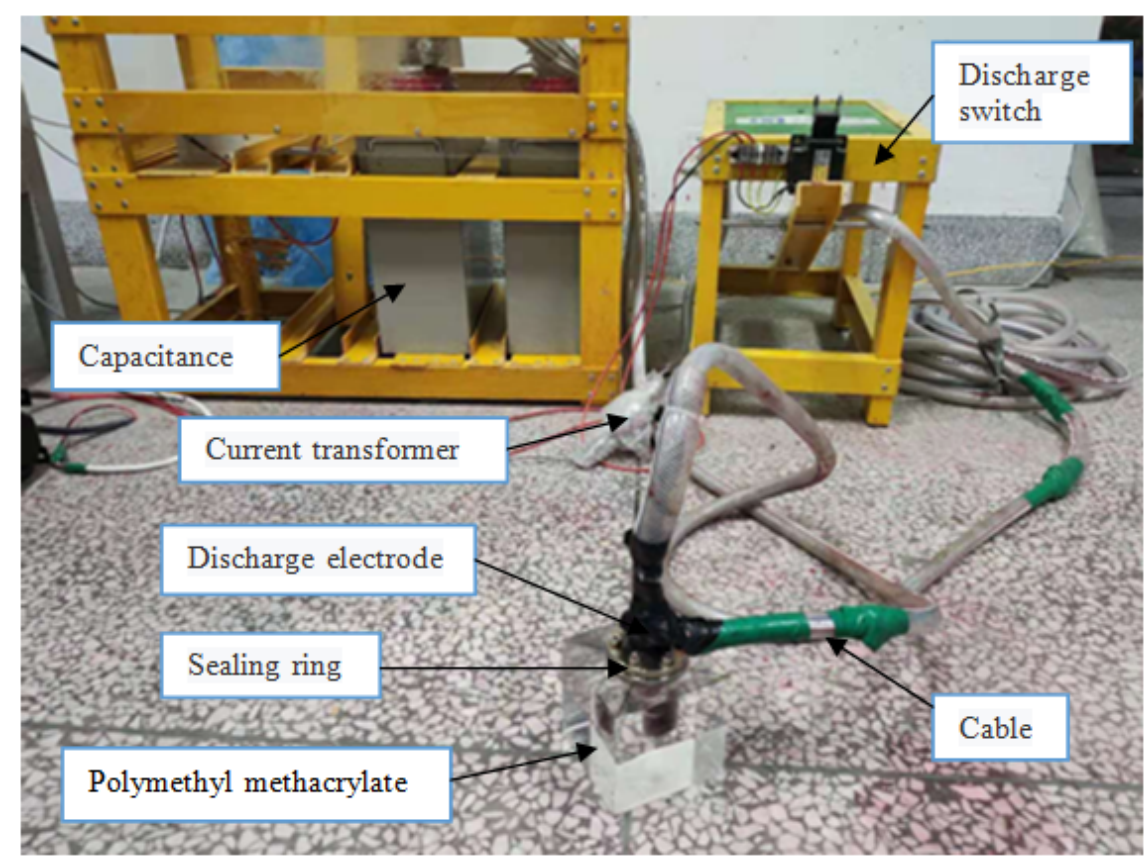

Fig. 3. Schematic of the experimental device

\section{Result analysis and discussion}

\subsection{Results and analysis of the PMMA visualization experiment}

PMMA was used to simulate the fracturing condition of open holes. The experimental results are shown in Fig. 4. Fig. (a) presents the result of cracking PMMA at $3 \mathrm{kV}$. The experimental samples show that a circular crack appears at the bottom of the well. The lengths of cracks extending toward the surroundings are basically the same. The maximum length of cracks is $12 \mathrm{~mm}$. Numerous sites on the well sidewall are deformed. Fig. (b) depicts the results of cracking PMMA at $4 \mathrm{kV}$. The experimental samples show that two main cracks and multiple secondary cracks appear at the bottom and on the sidewalls of the wells. The maximum length of the crack at the bottom is $15 \mathrm{~mm}$, the maximum length of the crack on the sidewall is $10 \mathrm{~mm}$, and the number of microcracks exceeds 4. Fig. (c)-1 and (c)-2 provide the results of fracturing at $5 \mathrm{kV}$. Penetrating cracks have appeared in the samples and include 5 main cracks, which show symmetrical " $\lambda$ " and " $Y$ " shapes. These cracks extend outward radically. Fig. (d)-1 and (d)-2 are the results of fracturing at $6 \mathrm{kV}$. Penetrating cracks are present in the samples, with the main cracks and the secondary cracks increasing continuously. Fig. (e)-1 and (e)-2 are the results of fracturing at $7 \mathrm{kV}$. The samples show "Y" and " $\lambda$ "-shaped net fracture, and although the number of the main cracks varies slightly from the number of cracks observed under 5 and $6 \mathrm{kV}$ fracturing, the total amount of the cracks increases sharply. The number of secondary cracks between the two main cracks has increased greatly, and the cracks exhibit a radial shape as a whole. The properties of the cracks of each group of PMMA are summarized in Table 1. The basic law of sample cracking is analyzed by plotting the curve of the relationship between the discharge voltage and the total number of cracks as shown in Fig. 5. The analysis in Table 1, Fig. 4, and Fig. 5 shows that the total number of cracks in PMMA increases continuously with the increase in discharge voltage. High voltage is associated with complex fracture morphology. 
Zhaoxuan Li, Tie Yan, Zhaokai Hou, Wenfeng Sun and Yang Shao/

Journal of Engineering Science and Technology Review 13 (4) (2020) 232 - 239

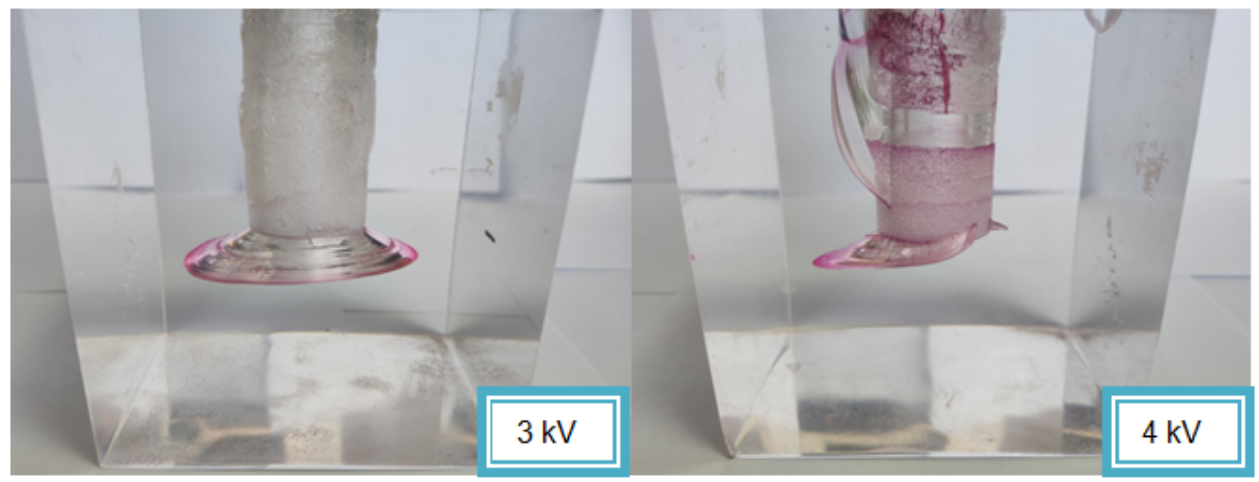

(a)

(b)

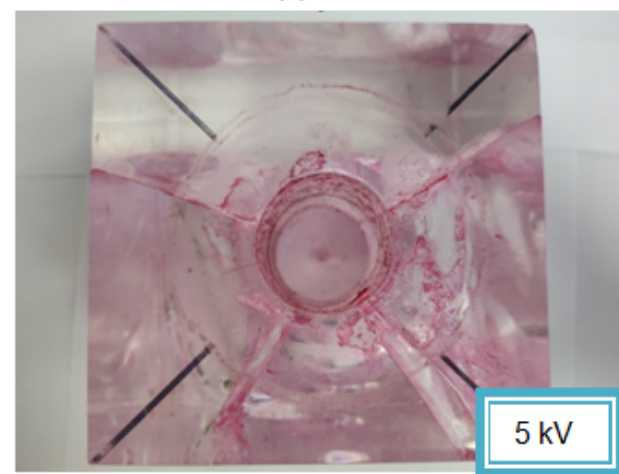

(c) -1

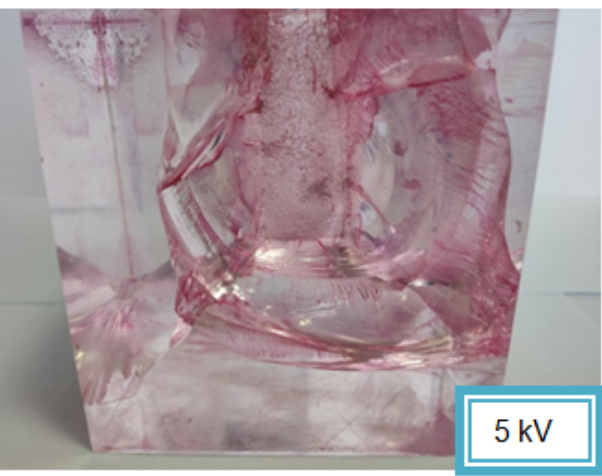

(c) -2

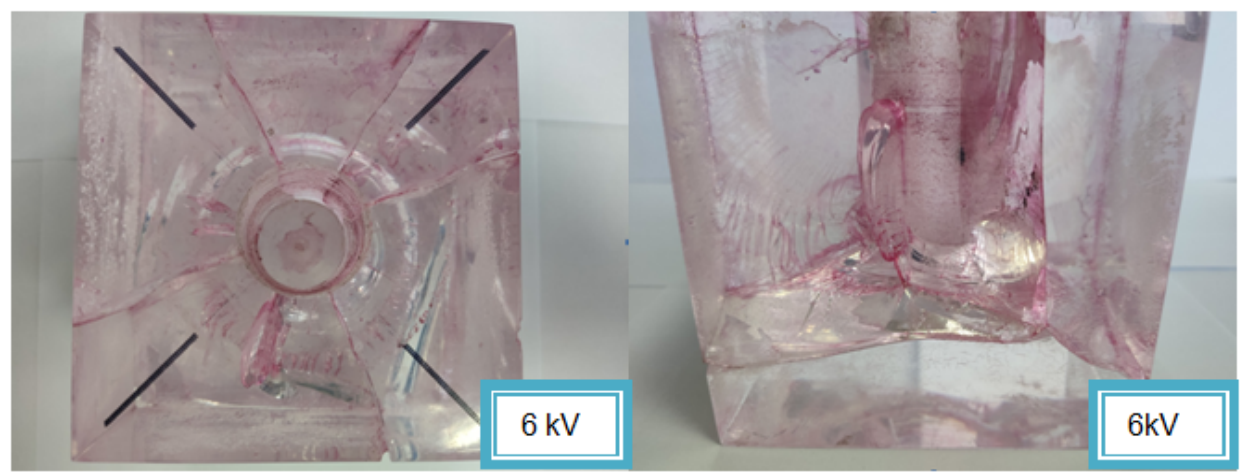

(d)-1

(d) -2

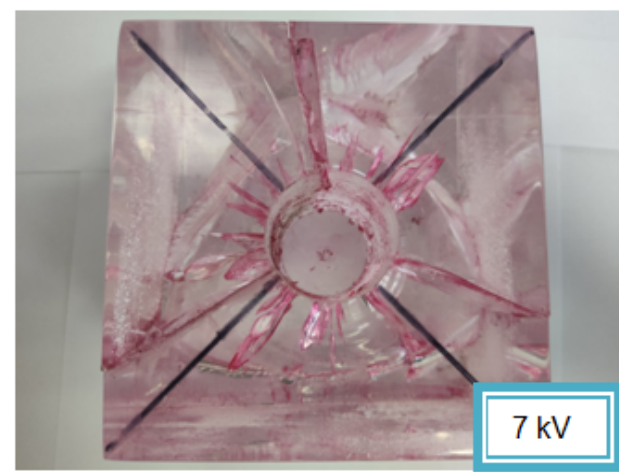

(e) -1

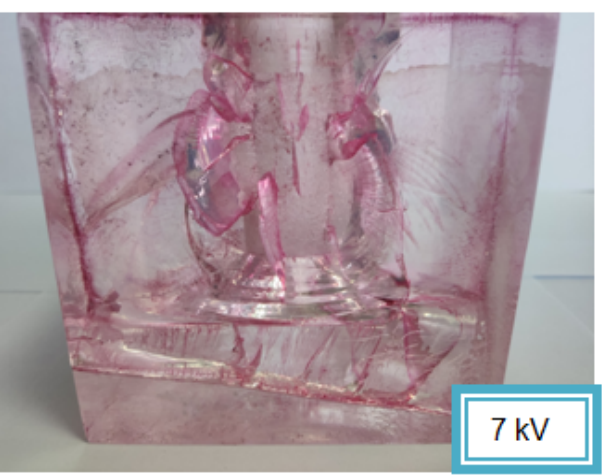

(e)-2

Fig. 4. Experimental PMMA fracturing results for each group

Table. 1. Summary of the fracture characteristics of PMMA

\begin{tabular}{|c|c|c|c|c|c|c|}
\hline Group & $\begin{array}{l}\text { Voltage } \\
(\mathrm{kV})\end{array}$ & $\begin{array}{l}\text { Number of } \\
\text { main cracks }\end{array}$ & $\begin{array}{l}\text { Number of } \\
\text { microcracks }\end{array}$ & $\begin{array}{l}\text { Max. length of horizontal } \\
\text { cracks (mm) }\end{array}$ & $\begin{array}{l}\text { Max. length of vertical } \\
\text { cracks (mm) }\end{array}$ & Crack morphology \\
\hline 1 & 3 & 1 & - & 12 & - & Wave form \\
\hline 2 & 4 & 2 & $>11$ & 17 & 15 & Wave form, microcracks \\
\hline 3 & 5 & 5 & $>31$ & Penetrating & Penetrating & $\begin{array}{l}\text { Wave form, "Y" and " } \lambda \text { " } \\
\text { cracks, microcracks }\end{array}$ \\
\hline 4 & 6 & 6 & $>40$ & Penetrating & Penetrating & $\begin{array}{l}\text { Wave form, " } \lambda \text { " cracks, } \\
\text { increased with microcracks }\end{array}$ \\
\hline 5 & 7 & 4 & $>76$ & Penetrating & Penetrating & $\begin{array}{l}\text { Wave form, "Y" and " } \lambda \text { " } \\
\text { cracks, }\end{array}$ \\
\hline
\end{tabular}




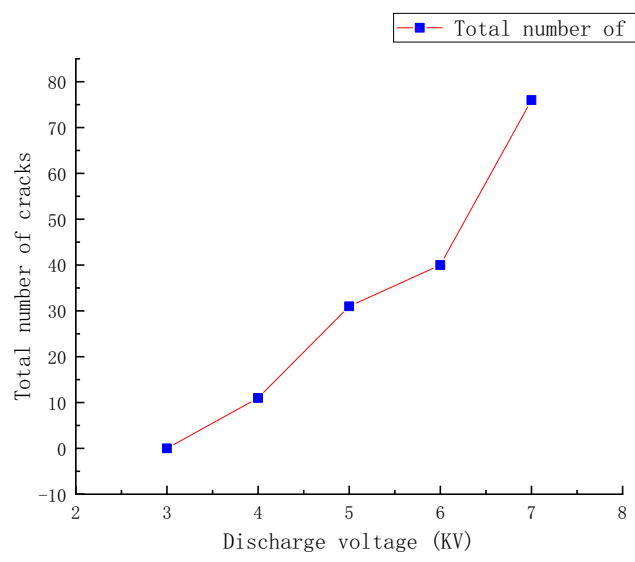

Fig. 5. Curve of the relationship between discharge voltage and the total cracks in PMMA
Cracks caused by hydraulic fracturing and plasma fracturing were compared by subjecting PMMA to hydraulic fracturing. The experimental results are shown in Fig. 6, which clearly shows that cracks induced by hydraulic fracturing are flat and that the surfaces of the cracks induced by plasma fracturing crack are undulating. Given that plasma fracturing can be considered as fracturing wherein a plasma discharge channel is used as the point vibration source to generate spherical shock waves, the cracks generated after plasma cracking are more difficult to close than those caused by hydraulic fracturing. Cracks induced by hydraulic fracturing are difficult to steer without applying triaxial pressure, and cracks caused by pulsed-plasma fracturing are complicated. As can be seen from Fig. 4, as the input energy increases, the cracks elongate, their shapes become increasingly complicated, and their number increases. Therefore, cracks caused by pulsed-plasma fracturing are more complicated than those caused by hydraulic fracturing.

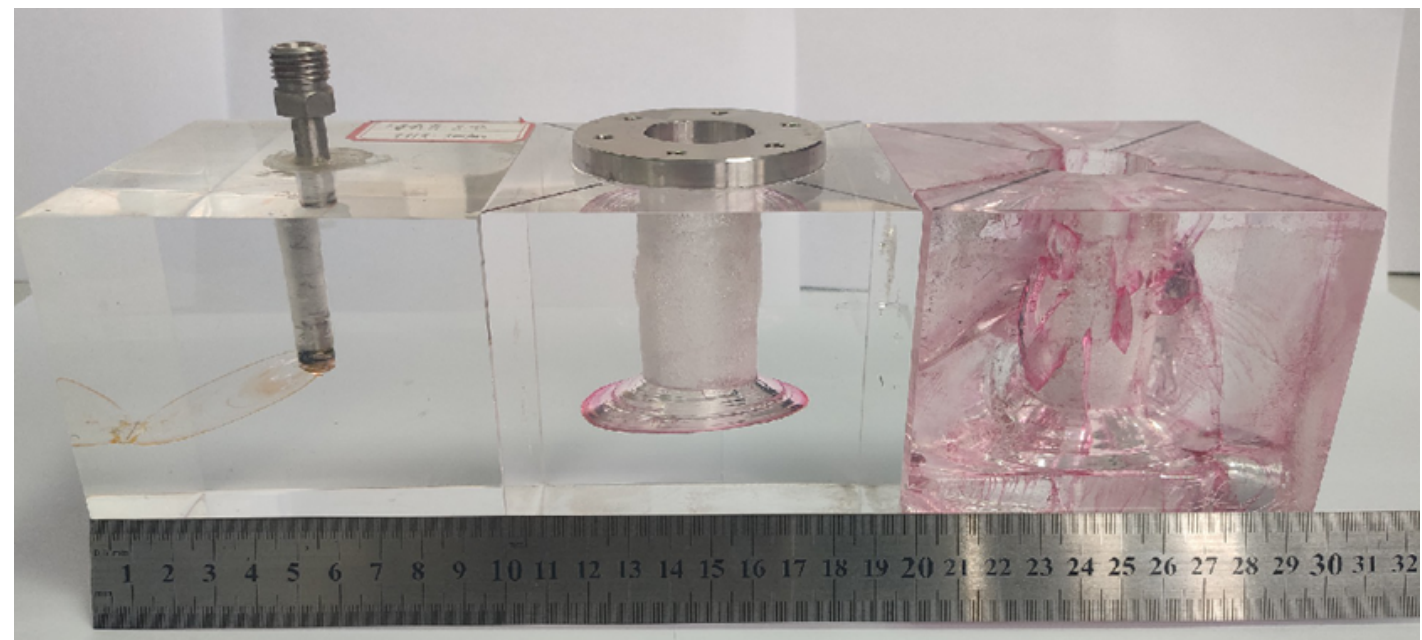

Fig. 6. Comparison between hydraulic fracturing cracks and plasma fracturing cracks

\subsection{Analysis and discussion of the numerical simulation results}

The model was subjected to a fracturing experiment by using falling triangular pulse loads of $9,12,15,20$, and $30 \mathrm{MPa}$. The pressure cloud diagram and crack extension of the specimen under external load are shown in Fig. 7. The figures from Fig. 7 (a) to Fig. 7 (e) show the conditions under $9,12,15,20$, and $30 \mathrm{MPa}$. The time of $200 \mu$ s was selected. The statistical data of crack length and width are summarized in Table 2, which shows that tensile failure occurs first and shear failure occurs under the load of 30 MPa. As depicted in Fig. 7 and Table 2, the width and maximum length of the cracks increase with the increase in load because high effective stress quickly exceeds the tensile strength of the rock, and the rock at the loading surface is broken instantaneously such that the shock wave spreads far. In addition, near the free surface, stress waves are reflected and converted into tensile waves, resulting in the wellknown surface spallation phenomenon.

A measuring point was selected on the loading and free surfaces, and a comparison chart of the stress time-travel curves of the same measuring points under multiple simulations was plotted as presented in Figs. 8 and 9. These figures show that effective stress reaches the peak value rapidly and then drops quickly with a shock-wave feature. The drop is followed by a slow rise and then a descent because the shock wave undergoes reflex on the free surface. The severe oscillation of the curve is the manifestation of insufficient stress. As the simulated applied load increases, the maximum peak and the reflex on the free surface increase. In Fig. 8, the arrow of the peak value of $30 \mathrm{MPa}$ indicates the post isosurface mode at the moment. This arrow shows that the pulsed plasma extends outwards in the form of a spherical wave. The arrow of the peak value of 30 $\mathrm{MPa}$ in Fig. 9 is the grid point mode at that moment, from which the diffusion path of the energy can be inferred.

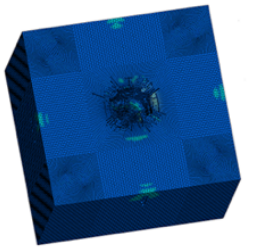

(a)

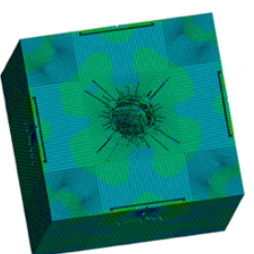

(d)

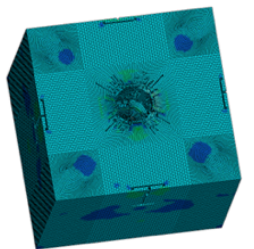

(b)

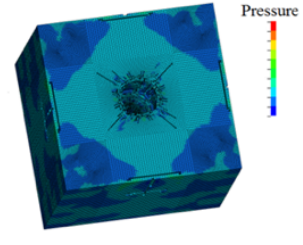

(c)

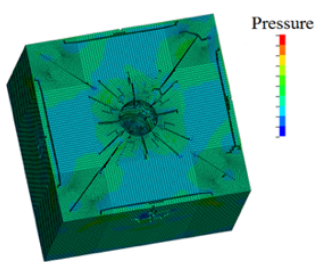

(e) 
Zhaoxuan Li, Tie Yan, Zhaokai Hou, Wenfeng Sun and Yang Shao/

Journal of Engineering Science and Technology Review 13 (4) (2020) 232 - 239

Fig. 7. Pressure cloud and crack expansion of the specimen as a function of external load

Table. 2. Statistics of fracture length and width in the numerical simulation of rock fracturing

\begin{tabular}{c|c|c|c|c|c|c}
\hline Sample No. & $\begin{array}{c}\text { Intensity of } \\
\text { applied load } \\
\text { (MPa) }\end{array}$ & $\begin{array}{c}\text { Max. length } \\
\text { of cracks } \\
\text { (mm) }\end{array}$ & $\begin{array}{c}\text { Max. width } \\
\text { of cracks } \\
\text { (mm) }\end{array}$ & $\begin{array}{c}\text { Number of cracks with } \\
\text { the observed length of } \\
\text { approximately } \mathbf{3 0} \text { mm }\end{array}$ & $\begin{array}{c}\text { Number of cracks with } \\
\text { the observed length of } \\
\text { approximately 20 mm }\end{array}$ & $\begin{array}{c}\text { Number of cracks with } \\
\text { the observed length of } \\
\text { approximately 10 mm }\end{array}$ \\
\hline 1 & 9 & 16 & 1.2 & 0 & 0 \\
2 & 12 & 20 & 1.5 & 0 & 1 \\
3 & 15 & 26 & 2.0 & 0 & 4 \\
4 & 20 & 29 & 2.1 & 0 & 8 \\
5 & 30 & 67.5 & 4.0 & 4 & 18 \\
\hline
\end{tabular}

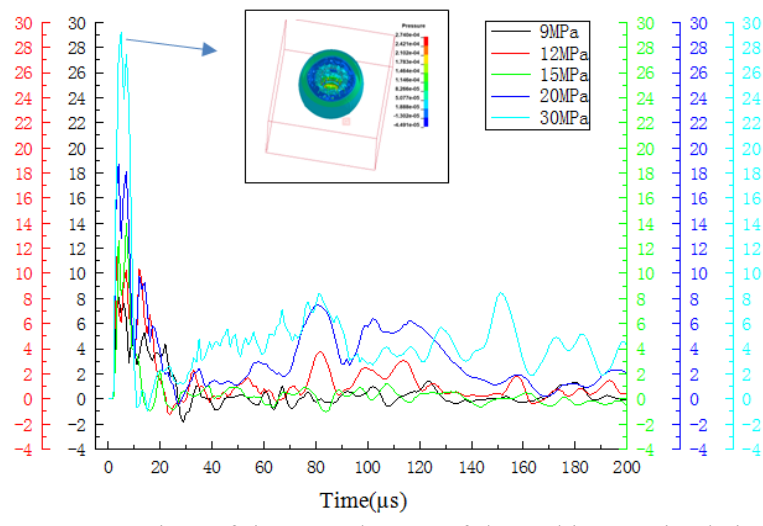

Fig. 8. Comparison of time travel curve of the multigroup simulations of stress at the same measurement points (loading surface)

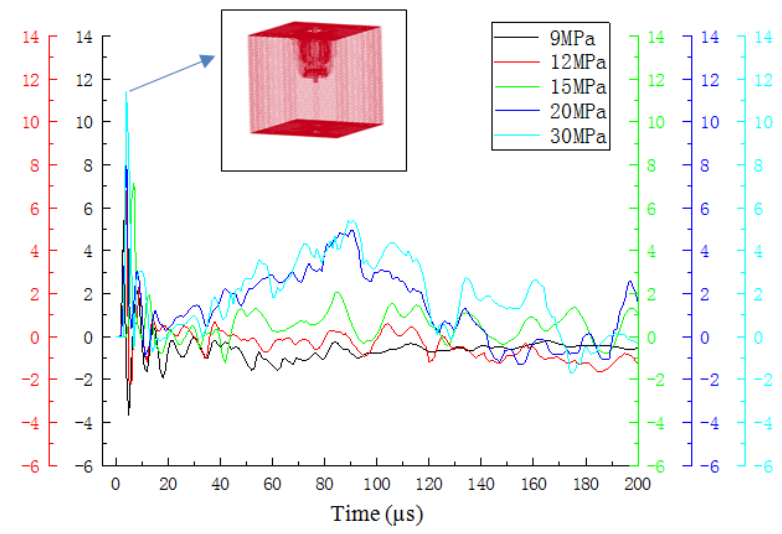

Fig. 9. Comparison of multigroup simulations at the same measurement points (free surface)

\section{Conclusion}

This study analyzed the mechanism of pulsed-plasma rock fracturing by combining tests and numerical simulation to explore and reveal the characteristics and mechanism of pulsed-plasma rock fracturing. The following conclusions were drawn:

(1) The model of stress distribution on the sidewalls of open holes during plasma fracturing suggests that rock fracturing pressure in pulse-plasma rock fracturing is related to the rock tensile strength, maximum horizontal principle stress, minimum horizontal principle stress, and pore pressure. Under the absence of confining pressure, the fracturing pressure of the rock is approximately equal to the tensile strength of the rock.

(2) The basic fracturing law of pulsed-plasma fracturing can be obtained intuitively by conducting a fracturing experiment on PMMA. The number and the complexity of cracks continue to increase with the increase in voltage. The comparative experiment with hydrofracturing shows that cracks formed by plasma fracturing exhibit a radial pattern with a large fracture density and wave-form characteristic.

(3) Numerical simulation reveals that the number, length, and width of rock cracks increase with the increase in applied load, and energy diverges in radiating spherical waves. Although the basic law of the crack initiation of pulsed-plasma rock fracturing has been obtained experimentally, study on this topic remains insufficient and presents a large gap. Data collection by experimental devices can be improved further, and the attenuation of shock-wave pressure after rock fracturing must be clarified. Subsequent studies on the characteristics of crack steering and the expansion pattern of the radial and axial combination of cracks are required.

This study combined laboratory experiments with theory to understand the crack propagation law of pulsed-plasma rock fracturing clearly. A visual experiment was performed to observe visually and describe the characteristics of fracture development. This experiment has a certain reference value for follow-up studies on pulsed-plasma rock fracturing. In contrast to rocks, PMMA is homogeneous. Although cracks in PMMA can be used to describe the shock wave propagation path well, they are idealized. Thus, PMMA is different from heterogeneous rocks, and how to compensate for this deficiency is the direction of future research.

\section{Acknowledgements}

This work was supported by the national natural science foundation of China (Study on the mechanism of plasma multi-field coupling rock breaking based on electric fracturing effect, No.51974090).

This is an Open Access article distributed under the terms of the Creative Commons Attribution License

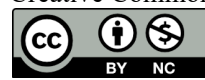

\section{References}

1. Ushakov, V., Klimkin, V., Korobeynikov S., "Impulse breakdown of liquids". Tomsk: Springer Science and Business Media, Russia,2007, pp.2-4.

2. Maurel, O., Reess, T., Matallah, M., "Electrohydraulic shock wave generation as a means to increase intrinsic permeability of mortar". Cement and Concrete Research, 40(12),2010,pp.1631-1638.
3. Oshita, D., Hosseini, S., Miyamoto, Y., "Study of underwater shock waves and cavitation bubbles generated by pulsed electric discharges". IEEE Transactions on Dielectrics \& Electrical Insulation, 20(4) ,2013,pp.1273-1278.

4. Iwasa, S., Kira, A., Maehara, H., "Pressure Measurements and Numerical Simulation of Underwater Shock Wave for Food Processing”. Materials Science Forum, 767,2014,pp.229-232. 
Zhaoxuan Li, Tie Yan, Zhaokai Hou, Wenfeng Sun and Yang Shao/

\section{Journal of Engineering Science and Technology Review 13 (4) (2020) 232 - 239}

5. Liu, B., Wang, D., Guo, Y.. "Effect of Circuit Parameters and Environment on Shock Waves Generated by Underwater Electrical Wire Explosion". IEEE Transactions on Plasma Science, 45(9),2017,pp.2519-2526.

6. Yongchao,Y.,Dingzhu, C., "Application of low frequency electric pulse oil recovery technology in un-derground mine". Well testing, 10 (1) ,2001,pp.60-62.

7. Mengyou, H.,Jianhua, Z.,Xing, Ai., "A review of gap state detection methods in edm". Electric processing and mould,3,2003,pp.17-20.

8. Fuze, J.,Xinglan, L.,Jianyong, L., "Application of low-frequency electric pulse plugging removal technology in oilfield production". Inner Mongolia petrochemical industry, 32(5),2006,pp.172-173.

9. Tianbo,W.,Baoguo, L.,Zhongmin, L., "“. Petroleum pipes and instruments, 2,2000,pp.11-14.

10. Cho, S., Lee, J., Kang, H., "Suggestion of dielectric breakdown strength as dynamic fracture property of rock materials". Lausanne:Rock Dynamics and Applications - State of the Art, Switzerland, 2013, pp.283-289.

11. Li, L., Qian, D., Zou, X., "Underwater electrical wire explosion: Shock wave from melting being overtaken by shock wave from vaporization". Physics of Plasmas, 25(5), 2018,pp.1-5.

12. Chen, W., Maurel, O., Reess, T., "Experimental study on an alternative oil stimulation technique for tight gas reservoirs based on dynamic shock waves generated by pulsed arc electrohydraulic discharges".Journal of Petroleum Science and Engineering, 88,2012, pp.67-74.

13. Timoshkin, I., Mackersie, J., MacGregor, S. "Plasma channel miniature hole drilling technology". IEEE Trans Plasma Sci, 32(5), 2004 , pp.2055-2061.

14. Schiegg, H. O.,Dland, A.,Zhu, G., "Electro-pulse-boring (EPB): Novel super-deep drilling technology for low cost electricity".Journal of Earth Science, 26(1),2015,pp.37-46.

15. Rim, G., Cho, C., "Design and testing of a rotary arc gap-switch for pulsed power". IEEE Transactions on Plasma Science, 28(5) , 2002 pp.1491-1496.

16. Decun, B., "Study on the characteristics of pulsed discharge shock wave under hydrostatic pressure and the fracture of rock mass". Doctoral Dissertation of Taiyuan technology university,China, 2018, pp.56-67.

17. Sun, Y., Zhou, J., Fu, R., “ Experimental study on rock fracturing by using pulsed power technology". In: 2014 IEEE International Power Modulator and High Voltage Conference (IPMHVC),Santa Fe,USA: IEEE,2014,pp.1-4.

18. Bing, S.,Zhiying, S.,Zhiyu Y., "Study on the characteristics of shock wave generated by pulsed discharge of liquid phase high pres-sure". In: The 16th National Plasma Science and Technology Conference,China: Fudan University, 2013,pp.322.
19. Bing, S., "Liquid phase discharge plasma and its applications". Shanghai: Science press, China, 2013,pp.2-3.

20. Kuznetsova,N.,Lopatin,V.,Burkin,V.,"Theoretical and experimental investigation of electro discharge de-struction of non-conducting materials". In: 2011 IEEE Pulsed Power Conference. Chicago,USA: IEEE, 2011, pp.1-7.

21. Khomeriki, S., Mataradze, E., Chikhradze, N., "Rock Directed Breaking Under the Impulse Load". IOP Conference Series: Earth and Environmental Science, 44(5), 2016,pp.52.

22. Madhavan, S., Doiphode, P., Chaturvedi, S., "Modeling of shockwave generation in water by electrical discharges". IEEE Transactions on Plasma Science, 28(5) ,2000,pp.1552-1557.

23. Chen, W., Maurel, O., Borderie, C., "Experimental and numerical study of shock wave propagation in water generated by pulsed arc electrohydraulic discharges". Heat and Mass Transfer, 50(5), 2014, pp.673-684.

24. Claverie, A., Deroy, J., Boustie, M., "Experimental characterization of plasma formation and shockwave propagation induced by high power pulsed underwater electrical discharge".Review of Scientific Instruments, 85(6) ,2014,pp.1-8.

25. Deroy, J.,Claverie, A., Avrillaud, G., “ Optical diagnostics for high power pulsed underwater electrical discharge characterization". Journal of Physics: Conference Series, 500(14),2014,pp.1-7..

26. Liu, Y., Li, Z., Li, X., "Energy Transfer Efficiency Improvement of Liquid Pulsed Current Discharge by Plasma Channel Length Regulation Method". Transactions on Plasma Science, 45(12),2017,pp.1-9.

27. Mao, R., De, P. J., Leon, F., "Experiments on Pulse Power Fracturing". In: 2012 SPE Western Regional Meeting, Bakersfield ,USA: SPE,2012,pp.1-16.

28. Rongyao, F., Yaohong, S.,Ailong, P.,Ailong, F., "Experimental study on fracturing with high vol-tage electric pulse in shale gas pro-duction". Strong laser and particle beam, 28(07), 2016,pp.186190.

29. Rongyao, F., Yaohong, S.,Xuzhe, X., "Effect of hydrostatic pressure on fracture performance of rock under plasma impact". Ex-plosion and impact, 38(5),2018,pp.1051-1056.

30. Yan, D., Bian, D., Zhao, J., " Study of the Electrical Characteristics, Shock-Wave Pressure Characteristics, and Attenuation Law Based on Pulse Discharge in Water".Shock and Vibration, 2016(6),2016, pp.1-11.

31.Usov, A., Tsukerman, V., Potokin. A., "The Experience in Development of Technique and Technology of Electric Pulse Disintegration of Rocks and Ores". Tenn:Springer International Publishing, USA,2016,pp.325-332.

32. Inoue, H., Lisitsyn, I., Akiyama, H., "Pulsed Electric Breakdown and Destruction of Granite". Japanese Journal of Applied Physics, 38(38) ,2014,pp.6502-6505. 